\title{
COMPORTAMENTO ELEITORAL VOLÁTIL E REELEIÇÃO: AS VITÓRIAS DE JAIME LERNER NO PARANÁ
}

\author{
Emerson Urizzi Cervi \\ Faculdade Internacional de Curitiba
}

\begin{abstract}
RESUMO
O artigo apresenta, com base em indicadores sócio-econômicos regionais e em resultados consolidados das votações para governador do estado Paraná em 1994 e 1998, elementos indicativos de alta volatilidade eleitoral que não podem ser captados em uma análise do agregado estadual. Analiso os resultados eleitorais dos pleitos para o executivo do Paraná a partir de um recorte geográfico, definindo os municípios como unidades de análise. A votação dos candidatos nos municípios do Estado é agrupada segundo o tamanho das unidades e de acordo com seu desenvolvimento econômico-social, indicado pelo IDH-M (Índice de Desenvolvimento Humano Municipal, de 1991). Os municípios são distribuídos em micro, pequenos, médios e grandes. Para estabelecer um parâmetro de desenvolvimento econômico-social, utilizo o Índice de Desenvolvimento Humano (IDH), reunindo os grupos de municipios em IDH muito baixo, IDH baixo, IDH médio e IDH alto. O objetivo do trabalho é identificar geográfica e socialmente o eleitorado dos principais candidatos ao governo do Paraná nas duas eleições em análise. A partir dai demonstro a existência de uma volatilidade eleitoral importante nas duas eleições vencidas por Jaime Lerner, que não é perceptivel quando se analisa o resultado agregado das votações. A questão de fundo do artigo diz respeito à discussão sobre o comportamento eleitoral nas democracias de massa, ou democracias de público, nas quais o eleitor é identificado como um sujeito do processo eleitoral que tem vontades e demandas permanentemente cambiáveis.
\end{abstract}

PALAVRAS-CHAVE: comportamento eleitoral; democracia de massas; volatilidade eleitoral; governo do Paraná; Jaime Lerner.

\section{INTRODUÇÃO}

Das principais concepções de democracia existentes, por mais díspares que se apresentem, todas têm um ponto em comum: desconsideram em maior ou menor grau a volatilidade do comportamento eleitoral como elemento-chave da análise dos sistemas democráticos. Trata-se de uma conseqüência indireta da falta de atenção que as teorias democráticas tradicionais têm com os efeitos da mídia no comportamento dos sujeitos que compõem as democracias, por mais que se tenha avançado nos conceitos como o de democracia de público, de Bernard Manin (1995) ${ }^{1}$, que apresenta as diferenças surgidas entre as democra-

\footnotetext{
1 Manin (1995) analisa as diferenças das democracias contemporâneas, que sofrem influência dos meios de comunicação de massa, denominadas de democracia de público, e as formas tradicionais de democracia, como a democracia de partidos e a democracia representativa. Em
}

cias deliberativas e democracias republicanas quando estas passam a sofrer a influência e os efeitos dos meios de comunicação de massa.

O próprio Manin, que introduz de maneira sistematizada no conceito de democracia os efeitos dos meios de comunicação, desconsidera em parte a volatilidade eleitoral como elemento fundamental desse sistema. Para ele, o que caracteriza a democracia de público é a relação contínua e quase direta entre representantes e representados, fazendo que os bons representantes sejam aqueles que conseguem melhor comunicar-se com os representados. Para ele, a elite política moderna é uma elite de comunicadores políticos. Em função do contato

síntese, ele afirma que na democracia de público a eleição dos representantes baseia-se em escolhas de pessoas confiáveis e na presença do comunicador, ao contrário da fidelidade ao partido, influência de notáveis e pertencimento a uma classe, que caracterizaram o processo de escolha eleitoral nas democracias tradicionais. 
constante, os representantes perdem autonomia em relação ao temas políticos e aos tratamentos dados a eles; sendo assim, os comunicadores políticos teriam que adaptar seus discursos às expectativas dos eleitores. Contudo, o autor não aborda os efeitos das possíveis mudanças dessas expectativas nos resultados eleitorais.

Entre as análises correntes da democracia brasileira cresce a dificuldade em identificar a volatilidade eleitoral em função do conceito de personalismo político. São constantes as considerações de que os eleitores identificam-se com os candidatos carismáticos e assim apresentam um comportamento eleitoral pouco racional. De fato, é possível levar em conta a identificação pessoal como fator relevante na definição do voto em uma democracia de público; porém, considerar que essa identificação é quase um pressuposto imutável, em que o eleitor vota repetidamente em determinado candidato com quem se identifica pessoalmente, é um equívoco, por desconsiderar a volatilidade do comportamento eleitoral.

O problema torna-se ainda maior quando é possível determinar volatilidade eleitoral mesmo em processos nos quais ela parece não existir. É o caso das duas eleições de Jaime Lerner para o governo do Paraná, em 1994 e em 1998, que teve $54 \%$ e $52 \%$ dos votos válidos, respectivamente. Esses números, no agregado estadual, indicam uma certa manutenção do capital eleitoral de Lerner nas duas disputas. No entanto, ao se substituir a análise agregada estadual pelo agregado dos municípios, é possível constatar grandes oscilações eleitorais nos dois pleitos, indicando alta mobilidade dos eleitores em relação ao candidato Lerner no período analisado.

Neste artigo, inicialmente faço uma breve revisão sobre as teorias do comportamento eleitoral e das diferentes formas de democracia. A partir daí, analiso o comportamento eleitoral por tamanho de município no Estado do Paraná nas duas eleições citadas acima para Governador do Estado. Por tratar-se de uma eleição majoritária, a análise da distribuição geográfica dos votos e de suas características pode explicar o comportamento dos eleitores e suas relações com os candidatos. A partir da análise geográfica da distribuição municipal dos votos é possível considerar que os eleitores de Lerner na primeira eleição não se mantiveram em 1998. A base geográfica do candidato a Governador em 1994 sofreu uma transformação significativa em 1998. Apesar dessa volatilidade, ele conseguiu ser reeleito. $O$ texto não busca explicar as motivações dos eleitores para a volatilidade, pois para isso seria necessário outro instrumento de coleta de dados, que permitisse conhecer as aspirações dos indivíduos, e é nesse sentido que não procuro explicar os motivos da mudança nas preferências dos eleitores de municípios de pequeno e grande portes do Estado. Trata-se da apresentação de dados que corroboram as teses de que existe algum grau de autonomização do eleitor frente aos candidatos nas democracias contemporâneas.

\section{TEORIAS SOBRE O COMPORTAMENTO ELEITORAL}

As análises sobre o comportamento eleitoral podem ser divididas em dois grandes grupos, um de matriz analítica macrossocial e outro microssocial, também conhecido como individualismo metodológico (CASTRO, 1994, p. 9). Em ordem cronológica, a primeira perspectiva considera fatores estruturais, culturais e históricos como formadores das esferas sociais, econômicas e políticas de uma sociedade. Esses fatores impõem clivagens sociais que na esfera política são representados por diferentes partidos políticos, com os quais parcelas do eleitorado identificar-se-iam e manifestariam seu apoio ou oposição.

Ainda no interior dessa perspectiva, análises marxistas enfatizam a importância de determinantes econômicos e da estrutura de classes como principais elementos de identificação entre líderes e liderados políticos. Por outro lado, uma corrente nãomarxista chamou a atenção para a variedade cultural a partir da qual se formam as clivagens sociais. Para ela, o comportamento eleitoral deve ser explicado pelo ambiente sócio-cultural em que vivem os eleitores e não simplesmente pela diferença entre classes sociais (FIGUEIREDO, 1991, p. 86).

A perspectiva macrossocial considera que grupos sociais distintos têm interesses diferentes e buscam uma representação política própria por meio de partidos ou líderes que representam os interesses do grupo. Isso é o que faria o eleitor direcionar seu voto em uma ou outra direção, ou até mesmo decidir-se pelo não-voto. Assim, a influência do grupo é um importante elemento explicativo da escolha eleitoral, pois pessoas que trabalham e vivem juntas tendem a votar nos mesmos candidatos. De acordo com essa perspectiva, ganham importância elementos psicossociais para a determinação do voto, e aparece como fator relevante a figura do líder de opinião: o líder de 
opinião de determinado grupo social consegue comunicar-se com seus iguais, influenciando-os na tomada de decisão do voto ${ }^{2}$. Ele possui uma posição central no grupo a que pertence e isso lhe garante melhores condições de recepção das informações e difusão de opiniões. Essa abordagem psicossocial na corrente macrossocial permite um avanço na teoria; até então era incapaz de explicar a variedade de comportamento eleitoral dentro dos grupos sociais, essas variações de comportamento são explicadas pelo surgimento ou pela substituição de líderes de opinião ${ }^{3}$. Além disso, a corrente psicossociológica considera como elementos determinantes do comportamento eleitoral percepções do próprio processo, tais como a identificação do candidato vencedor, o sentimento de obrigação de votar em uma disputa "apertada" e outros mais. Sendo assim, além das clivagens histórica, social e cultural dos grupos, os indivíduos apresentariam subclivagens de comportamento eleitoral, dado que o comportamento final dependeria de seus graus de interesse e informação a respeito das eleições.

Uma proposta teórica bastante distinta das anteriores foi sistematizada por Anthony Downs nos final dos anos 1950, baseada na perspectiva microssocial, ou do individualismo metodológico, e com elementos já distinguíveis em contratualistas como Rousseau e Hobbes. De acordo com essa proposta, seria possível explicar os comportamentos políticos considerando que os indivíduos são racionais e agem intencionalmente, procurando maximizar seus ganhos, tal como fazem os consumidores no mercado econômico (DOWNS, 1999, p. 58). Sendo assim, os efeitos do grupo seriam secundários na definição do comportamento eleitoral - mas não rejeitados. De acordo com essa corrente, o eleitor toma duas decisões relacionadas entre si: 1) participar ou não do processo eleitoral e, em caso positivo, 2) escolher determinado partido ou candidato - sempre considerando que a decisão tomada será a melhor para ampliar os seus ganhos individuais. Downs também chama a atenção para o fato de que a ideologia pode ser considerada um fator simplificador do universo político, uma vez que teria principalmente um

${ }^{2}$ Em última análise isso é o que causaria uma homogeneidade no comportamento eleitoral dos grupos sociais.

3 Uma das principais obras a partir dessa perspectiva é The American Voter, de Campbell, Miller e Converse (1964). caráter instrumental, facilitador do processo de tomada de decisão, como uma espécie de atalho. Uma vez que contribui para a caracterização dos partidos, a ideologia é um dos meios para obterse votos. Do ponto de vista dos eleitores ela passa a ser um recurso econômico que diminui os custos de procurar informações a respeito dos partidos e dos candidatos ${ }^{4}$. Ou seja, essa teoria apresenta um caráter microssocial até mesmo para fenômenos considerados predominantemente macrossociais, como é a situação da ideologia.

Parece claro que as diferentes correntes apresentam explicações incompletas para o comportamento eleitoral contemporâneo, na medida em que o eleitor é encarado como um sujeito que decide racionalmente em quem votar, mesmo que essa escolha seja condicionada pelo contexto em que ele insere-se. Como todo voto é uma ação intencional, logo racional ${ }^{5}$, trata-se de uma ação voltada para alcançar da maneira mais eficaz os objetivos pretendidos por cada eleitor. $\mathrm{O}$ importante é não esquecer que os atores políticos agem em situações estruturais e institucionais específicas. Essas situações condicionam suas opiniões, atitudes, seus objetivos e os instrumentos de que dispõem para perseguirem seus objetivos. Por isso, análises recentes levam em conta, por um lado, fatores sócio-econômicos e demográficos, além dos político-institucionais, e, por outro, a dimensão subjetiva e cognitiva do eleitor.

Há várias outras formas de abordagem do comportamento eleitoral de maneira direta ou indireta. Ainda assim, apesar dos avanços nas teorias, é comum encontrar a literatura tratando de maneira não central a idéia de que o eleitor tem efetivamente uma opinião política, que gera um comportamento eleitoral que pode ser mutável ou volátil. Seja quando movido pela busca da maximização de seus ganhos pessoais, seja quando movido em função de constrangimentos do grupo social a que pertence, esse comportamento e as opiniões são constantemente cambiáveis. Não se

\footnotetext{
${ }^{4}$ Dentre os vários autores que avançaram a teoria econômica básica de Downs, destaco a proposta de Teoria Unificada do Voto para o modelo espacial, de Merril e Grofman (1999), que postula principalmente a unificação analítica a partir dos conceitos de posição, direção e intensidade no contínuo de escolhas.

5 Essa afirmação é importante, pois a racionalidade defendida por Downs é uma racionalidade do método de tomada de decisão e não significa, necessariamente, resultados racionais.
} 
deve acreditar na existência de um eleitor majoritário que apresente um comportamento eleitoral estruturado rigidamente de maneira que seja constante e totalmente previsível.

\section{OPINIÃO PÚBLICA E VOLATILIDADE E- LEITORAL}

Em sociedade, as pessoas sempre procuram manter opiniões coerentes com as opiniões gerais do grupo a que pertencem. Para isso selecionam informações e mensagens que recebem, dando atenção àquilo com o que concordam e privandose do que as desagrada. Ao desprezar mensagens contrárias às atitudes do grupo, os homens vêem essas mesmas atitudes nos companheiros, que exibem tendências seletivas similares (CORREA, 1990, p. 12). Isso não significa que todos recebem e processam exatamente a mesma quantidade ou tipo de informação, ou que sejam influenciados pelos mesmos aspectos da vida social. Cada pessoa tem seu conjunto particular de experiências e seu próprio grupo de dados, mesmo selecionando e julgando o social de acordo com padrões gerais comuns. É fundamental estudar em que condições as atitudes geradas pela dinâmica de grupo modificam-se. Influências regionais ou de realidades próximas podem gerar um padrão de comportamento que terminará refletindo-se, em maior ou menor grau, na decisão do voto: por isso é válido estudar os resultados eleitorais a partir de recortes geográficos.

As atitudes sociais, incluindo o comportamento político, dependem da ativação de idéias, crenças, valores ou experiências que as pessoas têm. Essas experiências, valores e crenças são dinâmicos, cambiáveis; logo, o comportamento político está sujeito a modificações (SILVEIRA, 2000, p. 121). Momentos de crises ou circunstâncias especiais (como o afastamento ou rejeição ao grupo e submissão a propaganda contrária intensiva, quando impossível de ser desconsiderada) podem levar à reestruturação de atitudes e até mesmo a novas afiliações ${ }^{6}$, assim como ações de governos resultam em estímulos para a decisão do voto. A teoria do voto retrospectivo (FIORINA, 1981, p. 6) mostra a influência das percepções e análises sobre

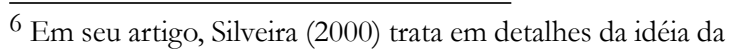
volatilidade eleitoral como uma conseqüência da nova forma de percepção dos eleitores, definida como a dimensão simbólica do voto. o que o governo fez pelos eleitores nos últimos anos no momento da decisão do voto.

É preciso considerar, de maneira complementar, que os homens nas sociedades modernas não pertencem a um único grupo. Existem posicionamentos anteriores e de largo espectro como classe social, cultura, e padrões que decorrem da faixa etária ou da região; grau de participação na comunidade, como local de trabalho e família, onde são desenvolvidas identificações e rejeições. Essa multiplicidade de fatores influenciadores, todos permeados pela presença da esfera pública por natureza que é a mídia, torna praticamente impossível identificar que tipo de espaço ou elemento é o principal responsável por determinado comportamento eleitoral.

Outro fator interveniente do comportamento eleitoral volátil é a já citada figura do líder de opinião. Dentro dos grupos não há uma homogeneidade de participação política entre as pessoas. Sempre existem aqueles mais ativos e capazes de expressar-se, normalmente mais sensíveis aos interesses do grupo e mais ansiosos de manifestarem-se em momentos importantes. Uma das funções desses líderes é a mediação entre os meios de comunicação e os demais componentes do grupo, pois se sabe há mais de meio século que os efeitos dos meios de comunicação não são iguais em todos os integrantes de determinado grupo (SILVEIRA, 2000, p. 125).

Antes dos estudos funcionalistas dos meios de comunicação, nos anos 1940, pressupunha-se que a maioria dos homens informava-se pelos noticiários e criações dramáticas parecidas com a realidade (por exemplo, as novelas). Mais tarde os funcionalistas descobriram que isso não está totalmente correto. Pesquisas empíricas mostraram que a maior parte das idéias dos indivíduos eram obtidas pelo contato com líderes de opinião e outros membros do grupo social mais próximo. $\mathrm{O}$ papel desempenhado por estes líderes é significativo. Os líderes de opinião atuam na seleção das fontes sociais de informação. Além de servirem de intérpretes do social na formação da opinião pública, são elos entre correntes diferentes de opiniões. Ou, para a análise microssocial, são os líderes de opinião que apresentam aos eleitores elementos necessários para a identificação de demandas e formação de determinado comportamento eleitoral. Além do líder de opinião, outro fator indispensável para a análise do compor- 
tamento eleitoral volátil tem sido o efeito da mídia na política. As novas características dos processos eleitorais inseridos no sistema de comunicação de massa são identificadas neste texto por "democracia de público", de acordo com a metáfora de Bernard Manin (1995).

Segundo a Teoria da Escolha Racional, considera-se que a decisão do voto é produto da ação racional individual e orientada por cálculos de interesse pessoal. Tendo em vista o objetivo de maximização de ganhos, o eleitor decide em quem votar a partir da análise dos benefícios que se pode obter no caso de vitória do candidato desejado. De acordo com o seu interesse o eleitor é capaz de selecionar partidos e candidatos em ordem de preferência e optar por aquele que lhe possibilitar a obtenção de maiores ganhos. Para conhecer como os eleitores irão comportar-se é preciso identificar os seus interesses e pontos de vista, uma vez que a mecânica do processo de decisão é conhecida. A Teoria da Escolha Racional não está preocupada com as motivações simbólicas das decisões eleitorais. Por mais que as motivações sejam afetivas ou emocionais, elas devem ser consideradas como as razões orientadoras do eleitor tendo em vista o objetivo de maximizar sua ação (SILVEIRA, 2000, p. 131). Mesmo o eleitor que votou em função de vínculos afetivos é considerado alguém que agiu racionalmente, porque através do seu voto ele procurou obter resultados conforme seu objetivo (satisfazer um afeto ou emoção).

O fenômeno da escolha eleitoral em função de atributos simbólicos, como tratada por Silveira, diferencia-se dos comportamentos políticos antigos. O voto é definido, de modo geral, em função do candidato e não do partido. Mas não se trata de um voto personalista tradicional, como um voto dado em função de devoção, subordinação ou fidelidade pessoal. $O$ voto desse novo eleitor muda de direção freqüentemente, dependendo da capacidade de sedução das diferentes alternativas políticas. Ele não está sujeito a coerções e imposições que o obriguem a seguir certa orientação. Não estando subordinado aos compromissos do tipo tradicional, o novo eleitor tem condições de assumir o comportamento volátil, independente ou infiel (idem, p. 134). Esse novo eleitor escolhe em determinadas circunstâncias em função de elementos conjunturais, que podem ser alterados; ele decide-se entre as diversas imagens disponíveis dos candidatos e estabelece com estes uma relação tênue de identificação, que pode ser modificada a qualquer momento.

Os aspectos sociais e subjetivos tratados anteriormente geram as condições necessárias para o surgimento de um eleitor politicamente disponível, que exerce papel ativo no processo eleitoral ao reagir de maneira positiva, negativa ou indiferente aos apelos dos candidatos. Por isso é que Manin lembra que na democracia de público o líder político precisa estar constantemente adaptando o seu discurso e as estratégias de contato com o eleitorado. Mesmo quando ocorre a identificação entre eleitor e candidato não há submissão total. O eleitor mantém-se independente, podendo sensibilizar-se pelos apelos de outras lideranças.

Nas diferenças entre o novo comportamento e o tradicional está a forma de identificação de representantes e representados. Os métodos tradicionais de contato como interação pessoal com os chefes políticos em assembléias ou comícios populares passam a ser substituídos. O novo tipo de escolha torna-se mais individual e não precisa do contato pessoal com o líder. As imagens dos candidatos e as informações transmitidas pela mídia desempenham a função de contato entre líder e liderado. Essas modificações políticas e tecnológicas é que permitem o surgimento de um eleitor que se identifica de modo pontual com os candidatos.

O comportamento volátil baseia-se na volatilidade das imagens dos candidatos transmitidas pela mídia. Por outro lado, os candidatos conquistam votos quando conseguem sensibilizar os eleitores. Como o eleitor é influenciado por diversos elementos, ele tem um conjunto de valores em constante transformação e acesso a vários líderes políticos e diferentes projetos políticos podem sensibilizá-lo.

As imagens construídas antes e no decorrer das campanhas eleitorais passam a ser decisivas tanto do ponto de vista retrospectivo quanto prospectivo para o comportamento eleitoral volátil. Depois de captadas dos meios de difusão de informações, essas imagens podem ser remodeladas de maneira individual, gerando um resultado final para cada eleitor.

O processo de definição do voto é o seguinte: um reduzido grupo de políticos profissionais participa da cena política como atores e a grande maioria da população toma contato com eles na 
qualidade de espectadores, identificando-se com alguns (idem, p. 136). A noção de "democracia de público", de Bernard Manin, traz subjacente a idéia de que mudanças políticas e tecnológicas estão alterando as características da democracia. Nessas condições ocorre um enfraquecimento dos partidos em função da forte presença da mídia, acentuando os atributos de comunicadores dos candidatos e o comportamento volátil dos eleitores.

Das diversas correntes teóricas apresentadas acima deve-se destacar para este texto que o eleitor da democracia de público é mais autônomo, volátil ou infiel do que em formações democráticas anteriores. Além disso, esse eleitor define seu voto a partir de cálculos racionais de ganhos, mas não se pode desprezar os constrangimentos sócioeconômicos e de acesso às informações direta ou indiretamente recebidas para tomar suas decisões. Por isso ganham importância as figuras do líder de opinião - que retransmite informações já analisadas e adaptadas à realidade específica de cada grupo de eleitores - e das campanhas eleitorais - que apresentam os candidatos, suas propostas e uma visão específica sobre a atuação dos governos anteriores.

\section{O ELEITOR VOLÁTIL E AS VOTAÇÕES PA- RA GOVERNO DO PARANÁ EM 1994 E 1998}

Em 1994 Jaime Lerner (então no PDT Partido Democrático Trabalhista) foi eleito Governador do Paraná no primeiro turno com 2 070970 votos, ou 54\% dos votos válidos. Em segundo lugar ficou o candidato do Partido Progressista (PP), Álvaro Dias, com 1455648 votos, ou 38\% dos votos válidos (TRE-PR, 1994). Também disputaram aquela eleição Jorge Samek (PT - Partido dos Trabalhadores), Rosemeri Vieira Kredens (PRN), Jaime Kreusch (PRONA - Partido da Reconstrução da Ordem Nacional), José Antonio Cardoso (PL - Partido Liberal) e Orlando Kulkamp (PSD - Partido Social-democrata), que dividiram os outros $8 \%$ dos votos válidos. Isso demonstra que o eleitor paranaense em 1994 dividiu-se entre dois candidatos principais ${ }^{7}$ : Álvaro Dias, ex-Governador, identificado com o grupo do então Governador Roberto Requião (PMDB Partido do Movimento Democrático Brasileiro), e Jaime Lerner, ex-Prefeito de Curitiba, candidato da oposição ao governo do Estado naquele ano.

\footnotetext{
7 Essa polaridade repetiu-se em 1998
}

Em 1998, treze meses depois de ter trocado o PDT pelo PFL, Jaime Lerner concorreu à reeleição para o cargo de Governador do Paraná. Essa foi a primeira campanha para Governador com a possibilidade de reeleição no Brasil. A chapa majoritária de Lerner em 1994 foi mantida, com a permanência da vice-Governadora Emília Belinati (então no PTB - Partido Trabalhista Brasileiro). A principal diferença da campanha anterior foi que a chapa do Governador não apresentou candidato ao senado em 1998. Com isso, o ex-Governador Álvaro Dias (PSDB - Partido da Social-democracia Brasileira) teve sua eleição para o Senado Federal facilitada. Em 1998 Lerner fez 2031241 votos, o que representou $52 \%$ dos votos válidos do Estado, sendo eleito também no primeiro turno. O Senador Roberto Requião (PMDB), candidato de oposição em 1998, fez 47\% dos votos válidos para o governo do Estado naquele ano. A eleição não teve segundo turno porque os outros dois candidatos, Julio César de Jesus (PSTU - Partido Socialista dos Trabalhadores Unido) e Jamil Nakad (PRONA), fizeram juntos menos de $2 \%$ dos votos válidos. Vejamos como distribuiu-se a votação majoritária de Jaime Lerner nos municípios paranaenses nas eleições de 1994 e 1998 :

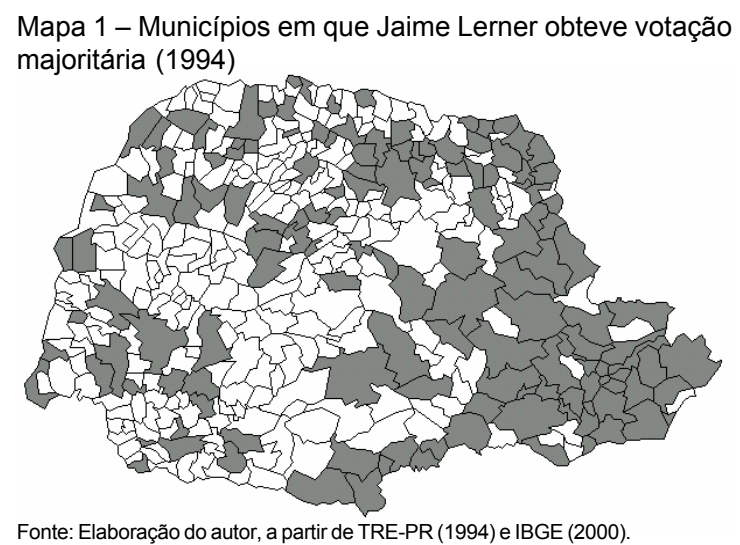

Mapa 2 - Municípios em que Jaime Lerner obteve votação majoritária (1998)

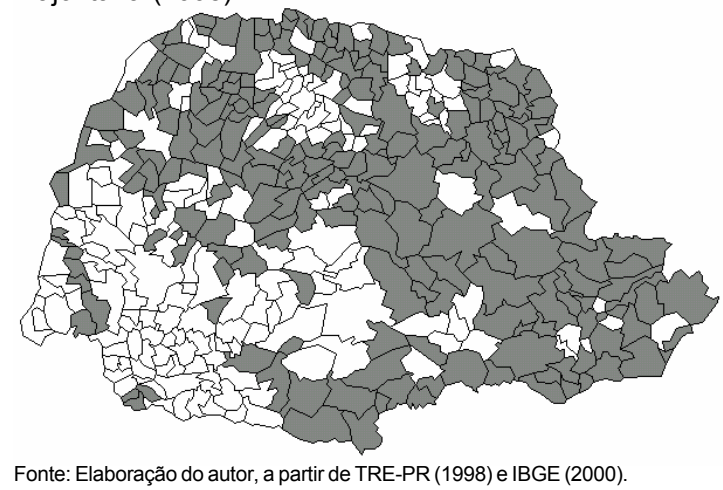


Nos mapas acima, os municípios em cinza são aqueles em que Jaime Lerner teve mais de 50\% dos votos válidos, ou seja, onde ele foi preferido pela maioria dos eleitores locais. A análise por votação majoritária nos municípios será utilizada no restante do texto e justifica-se por tratar-se de uma eleição majoritária estadual. É possível perceber que em 1994 Lerner foi o mais votado em municípios da porção leste do Estado. Em 1998, além de manter o predomínio sobre a região leste, a votação majoritária pró-Lerner avançou no norte do Estado e regrediu no extremo oeste. Além disso, em 1998 Lerner teve $2 \%$ a menos de votos válidos, porém o número de municípios em que ele apresentou votação majoritária foi superior a 1994. Isso é possível em função da concentração de votos em um número reduzido de grandes e médios municípios do Estado.

Com base nas informações dos resultados eleitorais e nos mapas acima, é possível imaginar que o quadro eleitoral paranaense para as eleições de Governador entre 1994 e 1998 ficou praticamente estável. Foram duas eleições polarizadas, a primeira entre Lerner e Dias e a segunda entre Lerner e Requião. O mesmo candidato, Jaime Lerner, venceu as duas disputas no primeiro turno com praticamente os mesmos índices de votos válidos: $54 \%$ em 1994 e 52\% em 1998. Nas duas campanhas o terceiro candidato teve uma votação insignificante, o que indica a polaridade na política local. A partir de dados do Tribunal Regional Eleitoral do Paraná (TRE-PR, 1994; 1998), é possível calcular o Número de Partidos Efetivos $(\mathrm{Ne})^{8}$ para o governo do Paraná: em 1994 foi de 2,22 e em 1998 ficou em 2,07. A chapa majoritária de Lerner não teve grandes modificações entre as duas campanhas. Apesar das mudanças de partido no final do primeiro governo, quando Lerner trocou o PDT pelo PFL (Partido da Frente Liberal) e a vice-Governadora Emília Belinati mudou-se do PDT para o PTB, os aliados e a base de sustentação do governo foram mantidos.

\footnotetext{
8 O índice de Ne é obtido a partir da soma dos quadrados das proporções de votos de cada partido concorrente ao cargo analisado, padronizando através da divisão pelo denominador um. Trata-se de um indicador agregado, que deve ser usado para a análise de como se distribuiu a votação dos eleitores em determinada votação. O objetivo é responder quantos partidos tiveram relevância de fato em dada eleição.
}

O mesmo nota-se entre os candidatos de oposição a Lerner nas duas disputas: eles eram politicamente próximos e ambos ex-governadores pelo PMDB. Embora Dias tenha sido candidato em 1994 pelo PP, ele foi Governador do Paraná entre 1987 e 1990 pelo PMDB; Roberto Requião foi Prefeito de Curitiba, Secretário de Estado do governo Dias e Governador do Paraná entre 1991 e 1994 pelo PMDB.

Porém, a análise da distribuição geográfica dos votos dos dois principais candidatos ao governo do Estado em 1994 e 1998, considerando características específicas dos municípios, mostra que essa aparente continuidade do comportamento eleitoral é falsa. Por tratar-se de uma eleição majoritária para o governo do Estado, é possível analisar o desempenho eleitoral dos candidatos em cada município e região. Para isso, considera-se o candidato com mais de $50 \%$ de votos locais como o vitorioso no município. Os municípios foram agrupados em função de dois critérios. O primeiro é o tamanho do município. Seguindo a distribuição feita pelo Instituto Brasileiro de Geografia e Estatística (IBGE) (2000) os municípios foram classificados em "micro", pequenos, médios e grandes". O outro critério foi o da divisão pelo IDH (Índice de Desenvolvimento Humano), da ONU (Organização das Nações Unidas) disponível para o Estado do Paraná. Os municípios foram agrupados em quatro grupos de IDH: muito baixo, baixo, médio e alto para a média paranaense ${ }^{10}$.

A análise da distribuição geográfica dos votos tem por objetivo identificar alterações no comportamento do eleitor nas diferentes regiões e condições sócio-econômicas do Estado em eleições distintas. Como a maioria dos estados brasileiros, o Paraná apresenta uma distribuição populacional e de atividade econômica desproporcional regionalmente. Na capital e em alguns pólos regionais notase o desenvolvimento de uma economia urbana mais aquecida do que na maior parte do interior, que em grande parte tem sua economia vinculada ao desempenho das safras agrícolas anuais. A grande maioria dos municípios paranaenses é de

\footnotetext{
9 Em rigor, por esse critério considero apenas o Município de Curitiba como grande no Estado. Como Londrina fica no limite entre médio e grande, optei por classificá-lo também como Município grande.

10 O IDH utilizado no texto foi medido com base em características sócio-econômicas dos municípios em 1991.
} 
porte micro e pequeno, com crescimento populacional praticamente nulo e em muitos casos negativo, com a economia baseada na produção agropecuária. Essas diferenças locais podem colaborar para marcar comportamentos eleitorais específicos, com apoio ao candidato que melhor adaptar sua estratégia discursiva ou recursos de campanha para a realidade local, como visto nas seções anteriores. Deve-se considerar também as particularidades do processo de ocupação do território paranaense. São identificados três momentos distintos da formação social paranaense. O Paraná tradicional, que compreende do nordeste ao sudeste do Estado, incluindo o litoral, foi ocupado ainda no Brasil Colônia. Era a região por onde passavam as tropas do Rio Grande do Sul para São Paulo e pode ser considerada a face conservadora do Estado. Já no início do século $\mathrm{XX}$, o norte e noroeste passaram a ser ocupados por migrantes paulistas e mineiros que buscavam terras mais baratas para fugir da crise da cafeicultura nos anos 1920 e 1930. Esses migrantes deram uma feição mais progressista ao Paraná. Nos anos 1940 e 1950 outra grande corrente migratória resultou na ocupação do extremo oeste e do sudoeste do Estado. Desta vez, a população migrante vinha do Rio Grande do Sul, Estado que começou o processo de industrialização e urbanização antes do Paraná, expulsando parte da população rural para outras regiões. Prova das particularidades regionais do Paraná é que no oeste e sudoeste o PDT e o brizolismo continuaram com força eleitoral nos anos 1990, ao contrário das outras regiões do Paraná que tiveram pouca influência da migração gaúcha.

É um equívoco considerar que em um Estado com 6,6 milhões de eleitores e 399 municípios não haja diferenças regionais na preferência eleitoral. Também é um erro acreditar que o comportamento do eleitor de uma região com determinadas características sociais tende a não se alterar ao longo do tempo. A análise geográfica do comportamento eleitoral pelo IDH tem a função de confirmar os resultados obtidos na análise da distribuição dos votos por tamanho de município. Considerando as características econômicas e demográficas do Paraná, de maneira geral os município menores tendem a ser mais pobres e apresentar um IDH menor, enquanto os municípios médios e grandes tendem a um IDH mais próximo da média ou acima dela. Como o IDH municipal disponível para o Paraná é de 1991, naquele ano existiam 323 municípios no Estado e esta será a base de dados para as análises com o índice.

Dados oficiais do TRE-PR sobre os resultados eleitorais de 1994 e 1998 mostram que existe uma tendência de comportamento eleitoral muito parecida nos municípios de pequeno porte e nos de IDH baixo. O mesmo vale para IDH alto e municípios de porte médio ou grande. Porém, esse comportamento é diferente nas eleições de 1994 e 1998. O que as informações mostram de fato é que apesar de Jaime Lerner ter mantido praticamente o mesmo índice de votação nas eleições de 1994 e 1998, a distribuição geográfica de seus votos sofreu uma profunda transformação entre as duas campanhas eleitorais.

Na votação de 1994 Lerner conseguiu elegerse principalmente com os votos de municípios de porte médio e grande do Estado. Ele foi derrotado pelo candidato do governo na grande maioria dos micro e pequenos municípios do interior, enquanto manteve-se como o mais votado em $100 \%$ dos municípios de grande porte e em $96 \%$ dos municípios de porte médio. Por outro lado, Lerner foi derrotado em $52,9 \%$ dos municípios de pequeno porte e em $75 \%$ dos micromunicípios, onde Álvaro Dias foi o grande vitorioso. A somatória do total de votos dos 27 municípios grandes e médios do Paraná em 1994 representava pouco mais de $40 \%$ do total da votação do Estado. Foi com base nos votos dos eleitores dos pólos urbanos regionais que Jaime Lerner conseguiu se eleger em 1994, como mostra a Tabela 1 a seguir ${ }^{11}$ :

Tabela 1 - Desempenho eleitoral de Jaime Lerner, por tamanho de Município (1994)

\begin{tabular}{lllrrr}
\hline \hline & & \multicolumn{3}{c}{ Desempenho Jaime Lerner (PDT) 1994 } \\
\cline { 3 - 5 } & & $\begin{array}{c}\text { Mais } \\
\text { votado }\end{array}$ & Derrotado & Total \\
\hline Tamanho do & Micro & Casos & 49 & 154 & 203 \\
municipio & $\%$ & $24,1 \%$ & $75,9 \%$ & $100,0 \%$ \\
\cline { 2 - 5 } & & 66 & 74 & 140 \\
& Pequeno & Casos & $47,1 \%$ & $52,9 \%$ & $100,0 \%$ \\
\cline { 2 - 5 } & & $\%$ & 24 & 1 & 25 \\
& Médio & Casos & $96,0 \%$ & $4,0 \%$ & $100,0 \%$ \\
\cline { 3 - 6 } & & $\%$ & 2 & & 2 \\
& Grande & Casos & $100,0 \%$ & $100,0 \%$ \\
\hline Total & $\%$ & 141 & 229 & 370 \\
& & Casos & $38,1 \%$ & $61,9 \%$ & $100,0 \%$ \\
\hline \hline
\end{tabular}

Fonte: Elaboração do autor, a partir de TRE-PR (1994) e IBGE (2000).

Fazendo um breve retrospecto da estratégia de campanha utilizada por Lerner e do processo de constituição de sua imagem para o eleitorado, é possível entender porque ele conseguiu esse

11 Em 1994 o Estado do Paraná possuía 370 municípios. 
desempenho eleitoral nas regiões com maior nível de urbanização. Toda a campanha de 1994 de Jaime Lerner baseou-se na proposta de transformação da economia do Paraná. Essa transformação passaria, necessariamente, pela mudança do perfil econômico do Estado, que era - e continua a ser - principalmente baseado na produção agrícola. Lerner propunha uma industrialização rápida e induzida pelo governo por meio de incentivos financeiros para grandes grupos transnacionais que tivessem interesse em investir na região sul do país. Sua estratégia de campanha foi claramente direcionada para o eleitor de centros regionais, onde os municípios já tinham a infraestrutura social que propiciasse o recebimento de investimentos do porte proposto. A relação de maior benefício com uma possível vitória de Lerner parecia mais adequada ao eleitor dos centros urbanos no momento de definir o voto. Ao mesmo tempo, Lerner creditava aos governos do PMDB o atraso econômico do Estado e a falta de perspectivas para os trabalhadores paranaenses.

A análise do desempenho eleitoral de Lerner em 1994 por IDH municipal indica a mesma tendência. Ele foi o mais votado em $64,7 \%$ dos municípios com IDH alto. Ao todo, 68 municípios enquadram-se na categoria IDH alto. Conforme o índice vai caindo, também cai o desempenho eleitoral de Lerner. Nos municípios com IDH médio ele teve $41,9 \%$ de maioria de votos; nos de IDH baixo ficou com $37,2 \%$ e nos de IDH muito baixo, $30,5 \%$.

Tabela 2 - Desempenho eleitoral de Jaime Lerner, por IDH municipal (1994)

\begin{tabular}{|c|c|c|c|c|c|}
\hline & & & \multicolumn{2}{|c|}{ Jaime Lerner } & \multirow[b]{2}{*}{ Tota } \\
\hline & & & $\begin{array}{l}\text { Mais } \\
\text { votado }\end{array}$ & Derrotado & \\
\hline \multirow[t]{8}{*}{ IDH } & Muito baixo & Casos & 29 & 66 & 95 \\
\hline & & $\%$ & $30,5 \%$ & $69,5 \%$ & $100,0 \%$ \\
\hline & Baixo & Casos & 32 & 54 & 86 \\
\hline & & $\%$ & $37,2 \%$ & $62,8 \%$ & $100,0 \%$ \\
\hline & Médio & Casos & 31 & 43 & 74 \\
\hline & & $\%$ & $41,9 \%$ & $58,1 \%$ & $100,0 \%$ \\
\hline & Alto & Casos & 44 & 24 & 68 \\
\hline & & $\%$ & $64,7 \%$ & $35,3 \%$ & $100,0 \%$ \\
\hline \multirow{2}{*}{ Total } & & Casos & 136 & 187 & 323 \\
\hline & & $\%$ & $42,1 \%$ & $57,9 \%$ & $100,0 \%$ \\
\hline
\end{tabular}

Fonte: Elaboração do autor, a partir de TRE-PR (1994) e IBGE (2000).

O candidato situacionista naquele ano, Álvaro Dias, apresentou um desempenho eleitoral oposto ao de Lerner. Ganhou na maioria dos municípios com IDH muito baixo, baixo e médio. Mas não teve maioria nos municípios com IDH alto. Como candidato próximo ao governo de então, Álvaro Dias claramente conseguiu atingir os eleitores do interior do Estado, tendo dificuldades em apresentar-se como o melhor candidato para atender às expectativas eleitorais nas médias e grandes cidades.

Para 1998, a análise da distribuição geográfica dos votos mostra que o quadro eleitoral foi bastante distinto, embora Jaime Lerner tenha sido reeleito no primeiro turno. Os dados do TRE mostram que, ao contrário de 1994, Lerner conseguiu os votos principalmente dos eleitores de micro e pequenos municípios, perdendo espaço nos municípios de porte médio. Ele foi o mais votado em 62,6\% dos micromunicípios paranaenses em 1998 e em $52,1 \%$ dos municípios pequenos. Nas cidades de porte médio ele perdeu a maioria, sendo o mais votado em apenas $44 \%$. Manteve a maioria de votos nos dois municípios aqui considerados de grande porte - Curitiba e Londrina. Neles, em 1998 Lerner contava com o apoio direto dos prefeitos: em Curitiba, Cássio Taniguchi, que pertenceu à equipe de governo de Lerner, e, em Londrina, Antônio Belinati, marido da vice-Governadora Emília Belinati. Roberto Requião (PMDB), candidato de oposição em 1998, teve a maioria de votos em $56 \%$ dos municípios de porte médio do Estado, mas não conseguiu manter a vantagem nos micro e pequenos municípios, reduto político do MDB e depois PMDB paranaenses nos anos 1970 e 1980, como pode-se ver a seguir:

Tabela 3 - Desempenho eleitoral de Jaime Lerner, por tamanho de Município (1998)

\begin{tabular}{llrrr}
\hline \hline & \multicolumn{3}{c}{ Jaime Lerner } \\
\cline { 2 - 4 } & & $\begin{array}{c}\text { Mais } \\
\text { votado }\end{array}$ & Derrotado & Total \\
\hline Micro & Casos & 144 & 86 & 230 \\
& $\%$ & $62,6 \%$ & $37,4 \%$ & $100,0 \%$ \\
\hline Pequeno & Casos & 74 & 68 & 142 \\
& $\%$ & $52,1 \%$ & $47,9 \%$ & $100,0 \%$ \\
\hline Médio & Casos & 11 & 14 & 25 \\
& $\%$ & $44,0 \%$ & $56,0 \%$ & $100,0 \%$ \\
\hline Grande & Casos & 2 & & 2 \\
& $\%$ & $100,0 \%$ & 168 & $100,0 \%$ \\
\hline Total & Casos & 231 & 399 \\
& $\%$ & $57,9 \%$ & $42,1 \%$ & $100,0 \%$ \\
\hline \hline Fonte: Elaboração do autor, a partir de TRE-PR (1998) e IBGE (2000).
\end{tabular}

O resultado eleitoral de 1998, com o favorecimento de Requião nos centros urbanos de porte médio, deu-se apesar do primeiro governo de Lerner ter priorizado a política de desenvolvimento econômico urbano, o que pode servir como indicador de descontentamento do eleitor dessas áreas com a política adotada. Nos mapas abaixo é possível visualizar a mudança no perfil da votação por tamanho de município nas duas eleições de Lerner. 
Mapas 3 e 4 - Votação majoritária de Jaime Lerner, por tamanho do Município (1994 e 1998)
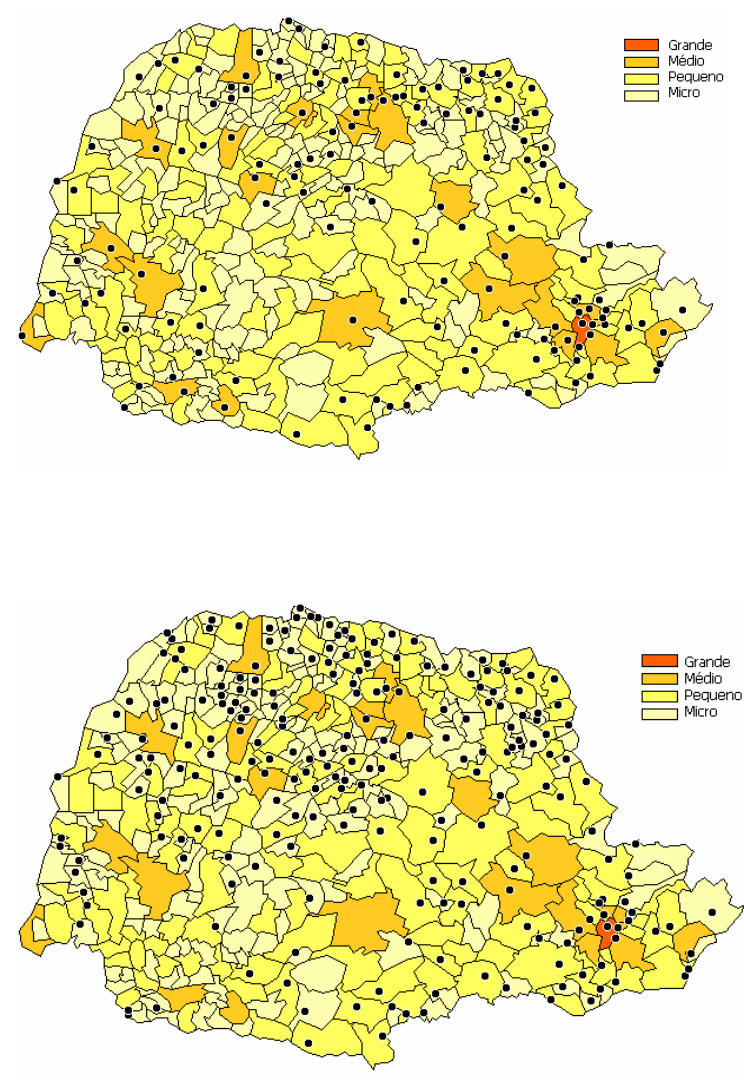

Fonte: Elaboração do autor, a partir de TRE-PR (1994; 1998) e IBGE (2000).

Os círculos pretos indicam os municípios em que Jaime Lerner teve maioria de votos em 1994 e em 1998. Comparando os dois mapas é possível perceber o "avanço" do candidato nos municípios micro e pequenos (com tons de amarelo mais claros), além de uma redução no número de municípios médios (tom alaranjado) em que Lerner obteve votação majoritária comparando 1994 a 1998.

Analisando o desempenho eleitoral dos candidatos ao governo em 1998 em função do IDH municipal, a inversão do comportamento eleitoral fica ainda mais evidente. Lerner foi o mais votado em $73,7 \%$ dos municípios com IDH muito baixo; em $58,1 \%$ dos municípios com IDH baixo; em $54,1 \%$ dos municípios com IDH médio e em apenas $44,1 \%$ dos municípios com IDH alto. Roberto Requião conseguiu ser o mais votado em 55,9\% dos municípios com IDH alto, tendo sido derrotado entre os municípios com IDH de médio a muito baixo.
Tabela 4 - Desempenho eleitoral de Jaime Lerner, por IDH municipal (1998)

\begin{tabular}{lllrrr}
\hline \hline & & \multicolumn{3}{c}{ Jaime Lerner } & \\
\cline { 3 - 5 } & & & \multicolumn{2}{c}{ Mais } & \\
& & & & \\
& & & & \\
& votado & Derrotado & Total \\
\hline IDH & Muito baixo & Casos & 70 & 25 & 95 \\
& $\%$ & $73,7 \%$ & $26,3 \%$ & $100,0 \%$ \\
\cline { 2 - 5 } & Baixo & Casos & 50 & 36 & 86 \\
& & $\%$ & $58,1 \%$ & $41,9 \%$ & $100,0 \%$ \\
\cline { 2 - 5 } & Médio & Casos & 40 & 34 & 74 \\
& & $\%$ & $54,1 \%$ & $45,9 \%$ & $100,0 \%$ \\
\cline { 2 - 5 } & Alto & Casos & 30 & 38 & 68 \\
& & Casos & $44,1 \%$ & $55,9 \%$ & $100,0 \%$ \\
\hline Total & $\%$ & $58,8 \%$ & $41,2 \%$ & $100,0 \%$ \\
\hline \hline
\end{tabular}

Fonte: Elaboração do autor, a partir de TRE-PR (1998) e IBGE (2000).

Uma explicação possível para essa mudança no comportamento eleitoral do paranaense nas eleições de 1994 e 1998 pode ser identificada na relação de maior dependência dos municípios pequenos e pobres com o poder público. Nas duas eleições, os candidatos do governo (Álvaro Dias em 1994 e Jaime Lerner em 1998) tiveram melhor desempenho no interior do Estado, onde está o eleitorado rural. Essa hipótese remete necessariamente à idéia do clientelismo e da intervenção direta do poder público em favor de determinado candidato em um processo eleitoral. Assim, as populações de municípios menores e mais pobres estariam mais sujeitas à influência de investimentos diretos do poder público na definição do voto do que os eleitores de municípios grandes e médios.

Outra hipótese para explicar a mudança no perfil do eleitor de Jaime Lerner poderia levar em conta a troca de partido ocorrida entre as duas votações. O PDT, partido de Lerner em 1994, teria mais penetração no eleitorado urbano, enquanto o PFL, partido de Lerner em 1998, no eleitor das pequenas cidades, reproduzindo uma tendência nacional de ambos os partidos. Porém, essa idéia não se sustenta quando aplicada aos candidatos de oposição a Lerner. Roberto Requião, que sempre pertenceu ao PMDB, também apresentou uma significativa mudança no perfil de seu eleitor, quando considerada a votação obtida por Álvaro Dias em 1994. Como afirmei no início do texto, o objetivo aqui não é encontrar motivos para a volatilidade eleitoral nas votações majoritárias, pois a natureza dos dados disponíveis não permite apresentar respostas conclusivas às hipóteses apresentadas acima. Independentemente das hipóteses que possam explicar a modificação no comportamento eleitoral, o que fica claro após a análise dos dados é que houve uma significativa volatilidade do eleitor paranaense nas duas eleições 
para Governador em questão, apesar dos resultados finais não permitirem a identificação imediata dessa dinâmica.

\section{CONCLUSÃO}

O eleitor das democracias contemporâneas possui características específicas e formas próprias de decidir o voto que não podem ser identificadas nas formações democráticas anteriores. A imagem que o eleitor constrói do candidato a partir de informações disponíveis nas esferas públicas da sociedade é fundamental para o comportamento do eleitor em uma "democracia de público". As ações do governo terão influência na imagem do candidato governista e as estratégias discursivas dos candidatos, aliadas às crenças e valores eleitorais, passarão a compor o imaginário eleitoral que terminará favorecendo um ou outro candidato. Esse imaginário eleitoral é composto por informações sociais mutáveis e, portanto, o voto perde a característica de perenidade, gerando um comportamento eleitoral volátil.

A reeleição de determinado candidato em uma "democracia de público" não significa necessariamente perda de volatilidade do comportamento eleitoral. Os resultados eleitorais para o governo do Paraná em 1994 e 1998 mostram que Jaime Lerner foi eleito por dois tipos distintos de eleitores. Enquanto sua imagem estava vinculada à oposição e formada a partir das expectativas de concretização de propostas de governo, contou com o apoio dos eleitores de determinadas regiões do
Estado. Depois, quando sua imagem perante os eleitores passou a ser composta a partir dos resultados das ações de seu primeiro governo, o eleitorado que o apoiava passou a ser de outras regiões. Esse indivíduo político continua disponível para entrar em contato com novas estratégias, principalmente por meio dos meios de comunicação de massa e dos formadores de opinião, aceitando as propostas de candidatos que melhor adequarem-se às demandas do eleitorado.

Sendo assim, é um equívoco afirmar que Lerner tem sua imagem pública formada para atender às expectativas dos eleitores urbanos, pois seu discurso tem como principais elementos de apelo o desenvolvimento sustentável, a qualidade de vida e a modernidade política, mas em 1998 não foi essa imagem que prevaleceu entre os eleitores que o reelegeram. Por outro lado, o eleitor que está sujeito a um grande volume de informações sobre os políticos e suas propostas durante as campanhas eleitorais tende a levar em consideração os efeitos de suas experiências passadas, aliadas a seus valores e crenças, que têm efeito de longo prazo, para definir em quem votar. Esse eleitor apresenta, em virtude dos fatores objetivos e subjetivos que o influenciam, um comportamento volátil, mesmo quando o candidato a cargo majoritário consegue ser eleito e reeleito em dois pleitos seguidos com praticamente os mesmo índices de votação. Isso não significa que haja, obrigatoriamente, um controle do eleitorado por parte da elite política vitoriosa.

Emerson Urizzi Cervi (ecervi@netbank.com.br) é Mestre em Sociologia pela Universidade Federal do Paraná (UFPR), doutorando em Ciência Política no Instituto Universitário do Rio de Janeiro (IUPERJ), e Professor de Ciência Política na Faculdade Internacional de Curitiba (FACINTER).

\section{REFERÊNCIAS BIBLIOGRÁFICAS}

CAMPBELL, A., MILLER, W. E. \& CONVERSE, P. E. 1964. The American Voter. New York : John Wiley.

CASTRO, M. M. M. 1994. Determinantes do comportamento eleitoral. A centralidade da sofisticação política. Rio de Janeiro. Tese (Doutorado em Sociologia). Instituto Universitário de Pesquisas do Rio de Janeiro.

CORREA, T. G. 1990. Contato imediato com a opinião pública. Os bastidores da ação política.
Porto Alegre : ed. G.

DOWNS, A. 1999. Uma teoria econômica da democracia. São Paulo : Edusp.

FIGUEIREDO, M. 1991. A decisão do voto. São Paulo : Sumaré/Associação Nacional de Pósgraduação e Pesquisa em Ciências Sociais.

FIORINA, M. P. 1981. Retrospective Voting in American National Elections. New Haven: Yale University Press. 
MANIN, B. 1995. As metamorfoses do governo representativo. Revista Brasileira de Ciências Sociais, São Paulo, ano 10, n. 29, p. 5-34, out.

MERRIL, S. \& GROFMAN, B. 1999. A Unified Theory of Voting : Directional and Proximity
Spatial Models. Cambridge, NY : Cambridge University Press.

SILVEIRA, F. E. 2000. A dimensão simbólica da escolha eleitoral. In : FIGUEIREDO, R. (org). Marketing político e persuasão eleitoral. São Paulo : Fundação Konrad Adenauer.

\section{OUTRAS FONTES}

TRE-PR. 1994. Relatório de resultados finais por candidato. Governador. www.tre-pr.gov.br : 01.ago.2002. Tribunal Regional Eleitoral do Paraná.

. 1998. Relatório de resultados finais por candidato. Governador. www.tre-pr.gov.br : 01.ago.2002. Tribunal Regional Eleitoral do Paraná.

IBGE. 2000. Censo demográfico 2000. Resultados do universo. www.ibge.gov.br : 01.ago.2002. Instituto Brasileiro de Geo-grafia e Estatística. 
This article has three different objectives. The first is to present and discuss the crisis in the implementation of administrative reform policies. That is followed by a selective review of the main contemporary theories that deal with this issue. Third, another theory is suggested: one which relates the crisis in implementing reforms to the problem of the limits in obtaining cooperation simultaneously with program objectives of fiscal adjustment and institutional change. The theory that is proposed argues that the tension between greater bureaucratic flexibility, on the one hand, and the demand for more rigor in internal systems of bureaucratic control, on the other, is a powerful causal mechanism which tends to generate successive crises in the implementation of such policies. For this reason, reforms tend to generate organized resistance to change, coordinating problems, problems of collective action and so forth. The article puts forth the argument that although this explanation can be considered of general validity with regard to administrative reform, it could prove much more critical for management reforms in which the contradiction between the goals of fiscal adjustment and institutional change is much more intense.

KEYWORDS: administrative reforms; public policies; public policy implementation.

$* * *$

VOLATILE ELECTORAL BEHAVIOR AND REELECTION: JAIME LERNER'S VICTORIES IN PARANA

Emerson Urizzi Cervi (Faculdade Internacional de Curitiba)

Based on regional socio-economic indicators and consolidated results from 1994 and 1998 elections for governor in the state of Paraná, this article presents data that demonstrate high levels of voting "volatility" that would not be perceived through data analysis at the aggregate state level. I analyze the electoral results from the gubernatorial dispute in Paraná through geographic divisions, using municipalities as my unit of analysis. Votes that candidates received in the diverse municipalities of the state are organized according to size of the latter and according to their levels of socio-economic development, as measured through the IDH-M (1991 Municipal Index of Human Development). Municipalities are classified as micro, small, medium and large. In order to establish a parameter of socio-economic development, I use the IDH, classifying municipalities into the following groupings: very low IDH, low IDH, medium IDH and high IDH. My aim is the social and geographic identification of the electorate that supported the major candidates for governor of Paraná for the above-mentioned consecutive elections. I show that there was an important level of electoral volatility in both of the elections which Jaime Lerner won, an aspect that is not perceived when analysis is based on aggregate election results. The deeper issue at stake here is related to the discussion of voting behavior in mass democracies, in which the voter is identified as a subject of the electoral process who has constantly changing demands and desires.

KEYWORDS: voting behavior; mass democracy; voting volatility, Paraná State Government; Jaime Lerner. 
Actes de la recherche en sciences sociales.

\section{LES RAISONS DE LA CRISE D'IMPLEMENTATION DE L'ETAT GESTION: PERFORMANCE ET AJUSTEMENT FISCAL}

Flávio da Cunha Rezende (Universidade Federal de Pernambuco)

Cet article se compose de trois buts différents: d'abord, il présente la crise d'implémentation des politiques de réforme administrative et en discute. Ensuite, il fait la révision des principales théories contemporaines abordant le sujet. Enfin, il suggère une théorie aditive qui met en rapport la crise d'implémentation des réformes et le problème des limites pour l'obtention de la collaboration simultanée en fonction des objectifs du programme d'ajustement fiscal et changement institutionnel. La théorie proposée prône que la tension entre plus de flexibilité burocratique, d'une part, et la demande d'une plus grande rigueur dans les systèmes internes de contrôle burocratiques, d'autre part, est un puissant mécanisme causal qui tend à générer des crises successives d'implémentation de ces propositions politiques. Aussi les réformes tendent-elles à générer une résistance organisée au changement, des problèmes de coordination, des problèmes d'action collective et d'autres problèmes. L'article argumente que, bien que cette explication soit valable d'une façon générale pour le cas des réformes administratives, il se peut que ce soit plus compliqué pour les réformes de gestion où la contradiction entre les objectifs d'ajustement fiscal et le changement intitutionnel est plus intense.

MOTS-CLÉS: réformes administratives; politiques publiques; implémentation des politiques publiques.

COMPORTEMENT ELECTORAL VOLAGE ET REELECTION: LES VICTOIRES DE JAIME LERNER DANS L'ETAT DU PARANÁ

Emerson Urizzi Cervi (Faculdade Internacional de Curitiba)

Cet article présente, données socioéconomiques de la région et résultats des élections pour le gouverneur de l'État du Paraná en 1994 et 1998 à l'appui, des éléments indicant une très grande volatilité électorale qu'on ne peut saisir dans une analyse de l'agregé de l'état. J'analyse les résultats électoraux du vote pour l'exécutif du Paraná à partir d'une coupe géographique, définissant les villes comme unités d'analyse. Les voix obtenues par les candidats dans les villes de l'état sont regroupées selon la dimension des unités et d'après leur développement socioéconomique, vérifié par l'IDH-V (Indicateur de développement humain de la ville en 1991). Les villes sont partagées en micro, petites, moyennes et grandes. Pour établir une référence de développement économique et social, j'utilise l' Indicateur de développement humain (IDH), classant les villes en IDH très bas, IDH bas, IDH moyen et IDH élevé. L'objectif du travail est d'identifier géographiquement et socialement les électeurs des principaux candidats au gouvernement du Paraná dans les deux élections analysées. Ensuite, je démontre l'existence d'une volatilité électorale importante dans les deux élections remportées par Jaime Lerner ce qui n'est pas saisi lorsqu'on analyse le résultat agrégé des voix. L'article discute notamment du comportement électoral dans les démocraties populaires où l'électeur est considéré comme l'agent du processus électoral dont les inclinations et demandes changent en permanence.

MOTS-CLÉS: comportement électoral; démocratie populaire; volatilité électorale; gouvernement du Paraná; Jaime Lerner. 